\title{
Comparative evaluation of powertrain concepts through an eco-impact optimization framework with real driving data
}

\author{
Arved Esser $^{1}$ (D) Tobias Eichenlaub ${ }^{1}$ (D) Jean-Eric Schleiffer ${ }^{1}$ (D) \\ Philippe Jardin ${ }^{1}$ D . Stephan Rinderknecht ${ }^{1}$
}

Received: 30 September 2019 / Revised: 19 March 2020 / Accepted: 12 July 2020 /

Published online: 25 July 2020

(c) The Author(s) 2020

\begin{abstract}
The assessment of the ecological impact of different powertrain concepts is of increasing relevance considering the enormous efforts necessary to limit the global warming effect due to the man-made climate change. Within this contribution, we adopt existing methods for the optimization of electric and hybrid electric powertrains using a vehicle simulation environment and derive a method to identify the ecological potential of different powertrain concepts for a set of technological parameters in the reference year 2030. By optimizing the parametrization for each powertrain concept and by adapting the respective operating behaviour specifically to minimize the ecological impact, a reliable and unbiased comparison is enabled. We use our optimization environment with the Real Ecological Impact as objective function to compare different powertrain concepts on driving profiles that are based on real driving data recorded in Germany. Despite the fact that all of the considered driving profiles contain trips of similar length, their respective optimized powertrain concepts are different. Plug-In Hybrid vehicles achieve the greatest potential for long-range capable vehicles and are least sensitive to different driving profiles.
\end{abstract}

Keywords Ecological impact · Powertrain concepts · Powertrain optimization · Driving profiles

\section{Introduction}

Throughout the last decades climate change has been identified as a key threat to humanity as a whole (IPCC 2014). That is why ecologically sustainable solutions to inherit global warming are subject to numerous research efforts in different areas.

Arved Esser

esser@ims.tu-darmstadt.de

1 Institute for Mechatronic Systems in Mechanical Engineering, Technical University

of Darmstadt, Otto-Berndt-Straße 2, 64287 Darmstadt, Germany 
Individual mobility in form of passenger vehicles holds a significant share of the overall greenhouse gas (GHG) emissions and is most likely going to be part of our mobility solution for upcoming decades. As such, a decrease of GHG emissions for this sector has to be accomplished. One way to reduce these emissions is to identify vehicle powertrain concepts with the lowest ecological impact, as it is done in life cycle assessment methods, and replacing current technology with these new concepts.

In state of the art studies, the assessment of powertrain concepts is carried out by analysing characteristic series production vehicles with regard to their GHG emissions. The result of these studies are comparisons between the underlying vehicles and do not allow general statements about specific powertrain concepts. To allow a comparison without relying on series production vehicles, a comprehensive analysis with constraints for the operational phase, the expected development of future energy mix including renewable energy sources and more has to be carried out. As the basis for this analysis, we derive an objective measure, the so called Real Ecological Impact (REI). Within this contribution we introduce this criterion as result of a life cycle assessment which includes emissions in production, operational and end-of-life phases. The REI is then used as the objective function of an optimization problem to find the best possible parametrization for specific powertrain concepts under given constraints, especially regarding the underlying driving profile within the operational phase. Our previous results show that, in case of short-range vehicles, battery electric vehicles (BEV) have the lowest REI (Esser et al. 2019). That result is confirmed by state of the art studies for short-range mobility (Helms et al. 2016; Wietschel et al. 2019). Therefore, as a driving profile constraint, we focus on vehicles with long-range capability for which studies come to different results, as shown in Sect. 2. The analyzed concepts include representatives of the following powertrain classes: internal combustion engine vehicle (ICEV) class, BEV class, plug-in hybrid electric vehicle (PHEV) class and fuel cell electric vehicle (FCEV) class. Since we optimize the parametrization of each specific powertrain concept regarding the REI, a common evaluation basis is provided and the comparability between the different technologies for specific driving profiles is enabled.

In Sect. 2, we show the state of the art concerning life cycle assessment and powertrain optimization. Section 3 gives a description of the derived optimization framework. Sections 4 and 5 present the basis for the evaluation in form of driving profiles and the vehicle simulation model, respectively. We are then going to discuss the results for different driving profiles with regard to specific powertrain concepts.

\section{State of the art}

To quantify the ecological impact of different powertrain concepts, a life cycle assessment is conducted. Regarding the quantification of the impact on global warming, the balancing of the Global Warming Potential for a time horizon of 100 years (GWP100) is the most established measure (EPA 2019). It allows the evaluation and combination of different GHG emissions. Many different studies have been 
performed comparing the GWP100 of powertrain concepts. The area of interest for our study are the boundary conditions within Germany.

Most of the studies mainly dealt with a scenario with short required range (Helms et al. 2016; Wietschel et al. 2019). For this scenario, BEV with a resulting moderate required battery capacity usually perform best, especially if future scenarios with predicted improved electricity mixes are regarded. A smaller number of studies is concerned with long-range capable vehicles, which is the focus of this work. The results for long-range capable vehicles in literature are less homogenous:

Wietschel et al. (2019) are comparing long-range capable BEV and ICEV concepts for the boundary conditions in Germany in 2019, identifying overall better results for the BEV. Only in the case of executive vehicles and very long ranges of $800 \mathrm{~km}$, the ICEV with diesel engine outperforms the BEV. The effects of battery weight on the consumption, the specific design of the powertrain and the consideration of further powertrain concepts, like PHEV and FCEV, are not included in their study.

Helms et al. (2016) perform a very detailed analysis of the life cycle emissions of $\mathrm{BEV}$ and a comparison of different powertrain concepts for the reference years 2016 and 2030. A BEV with $250 \mathrm{~km}$ range, which still does not fulfil our definition of long-range capability (350 $\mathrm{km}$ range) within the work, is analysed additionally to shorter ranges. The results indicate that as of 2016, long-range capable BEV lead to increased emissions compared to ICEV and PHEV concepts. By 2030, they will achieve a significantly better balance than the ICEV concepts and a slightly better balance compared to the considered PHEV concepts according to this study.

In ISE (2019) the authors compare the GPW100 of BEV and FCEV for the time periods 2020-2030 and 2030-2040. In their study FCEV achieve smaller GWP100 values for required ranges above $250 \mathrm{~km}$. Concerning short-range, the BEV are more suited. Further, powertrain concepts like PHEV were not considered.

In all of the mentioned studies, characteristic vehicles for all powertrain concepts were defined based on existing series production vehicles and typical design parameters of the powertrain like the battery capacity. Additionally, typical consumption values have been assigned. This approach is suited to evaluate the current use of powertrain technologies but cannot depict their respective potential of the powertrain concept to reduce the GWP100 as they were not dedicatedly optimized to achieve a minimum GWP100.

For this purpose, in this contribution existing methods for the optimization of electric and hybrid electric powertrains are utilized, adapted and extended for the application of a GWP100 minimization. We will refer to the summarized GWP100 for the entire life cycle for the optimization of powertrain concepts considering representative drive cycles as the REI within this work.

In Eghtessad et al. (2015), a multi-objective optimization method with focus on the technical performance indicators energy efficiency is presented. Here, driving performance as well as an economic performance indicator for powertrain costs for the comparative evaluation of different BEV class powertrains with different transmissions are considered. In order to accelerate the evaluation within the optimization process using a genetic algorithm, mathematical meta-models are applied which are generated by means of design of experiments on the basis of a physical simulation 
model. This involves searching for optimal parametrizations of the powertrain components, whereby the components can be adjusted using configurable basic parameters in order to minimize an objective function. The objective function is composed of a weighted sum of the individual performance indicators in each category to be evaluated. Meier (2013) extends this approach for the comparison of two different hybrid electric powertrains. Based on e.g. Ebbesen et al. (2012), a nested two-stage process is realized: There is both, the challenge of the parametrization of the powertrain itself (sizing of powertrain components, definition of transmission ratios, etc.) as well as the parametrization of the operating strategy. Thereby, the operating strategy is iteratively adapted for each powertrain variant in order to exploit the potential of the powertrain parametrization to the fullest.

Stochastic driving cycle synthesis methods can be used to generate short but representative driving cycles that represent large sets of driving data in a compressed manner. This approach, also applied in Eghtessad (2014), enables an efficient evaluation of powertrain parametrizations within the optimization framework based on the characteristics of the whole driving data set.

The approach of our contribution is to pick up on these methods and use simplified simulation models instead of mathematical meta-models to increase the computing efficiency. By doing so, a great variety of different powertrain concepts and parametrizations can be investigated on different driving profiles within the optimization process. The result is an optimal parametrization for each powertrain concept and a specific driving profile which enables an unbiased comparison.

\section{Optimization framework}

In order to enable a comparison between different powertrain concepts in the sense of a benchmark, the interactions between the individual components, the impact of the users behavior on powertrain efficiency as well as the impacts of the component sizing in the different phases of the life cycle must be taken into account. The sizing of the powertrain components and the specific set of powertrain parameters-in the following summarized as the parametrization of a powertrain concept, i.e. a variant-have a significant impact on the evaluation of its REI. Thus, an accurate parametrization with the aid of a holistic overall system optimization approach is needed and an optimization framework is developed to determine the optimal powertrain parametrization.

The evaluation of performance indicators in the operational phase like consumption by using real driving data is a fundamental part of the parametrization process of powertrain variants. A method, based on Esser et al. (2018) and further, described in Sect. 4, is used to synthesize representative driving cycles. The extensive database is thereby reduced to a necessary minimum. This enables a computationally efficient evaluation of powertrain concepts based on real driving data with aid of a vehicle simulation with a generic powertrain model described in Sect. 5. To achieve an estimation of the actual potential of powertrain variants, an operating strategy based on a locally optimal control approach, called Equivalent Consumption Minimization 
Strategy (ECMS) (Paganelli et al. 2002; Serrao et al. 2009), is adapted for each parametrization of a powertrain concept.

The objective function, which is minimized using a genetic algorithm, is the REI. Thus, it is not only made up of the greenhouse gas emissions during the operational phase, but is considering the entire life cycle. The production phase emissions, in particular, are strongly influenced by the sizing of the components.

Figure 1 shows a schematic overview of the developed optimization environment. For each powertrain concept, the minimum REI is determined based on a representative driving cycle by an optimal sizing and parametrization of the respective components. In this way, a reliable and unbiased basis for the comparison of different powertrain concepts is created.

The feasibility constraints of the simulation environment ensure that all powertrain concept parametrizations are able to follow each of the given driving cycles and that the vehicles fulfill the range requirements. Furthermore, the fundamental drivability of the resulting powertrain parametrizations during the optimization process is ensured by additional technology-neutral design constraints. The generated vehicles must be able to achieve a launch acceleration of $2.5 \mathrm{~m} / \mathrm{s}^{2}$ on a slope of $30 \%$, accelerate to $60 \mathrm{~km} / \mathrm{h}$ in $7 \mathrm{~s}$ and achieve a residual acceleration of $0.33 \mathrm{~m} /$ $\mathrm{s}^{2}$ at $180 \mathrm{~km} / \mathrm{h}$. Furthermore, to account for the idea of locally emission-free city driving, all parametrizations of powertrain concepts that can drive purely electric must achieve an electric range of $60 \mathrm{~km}$. Based on the calculated energy demand in the operational phase as well as the estimated parametrization-dependent weights of components, the REI is finally determined with the help of emission factors from literature. The determined $\mathrm{CO}_{2}$ emissions in the production of different vehicle components are shown in Fig. 11 for the reference driving profile, which will be introduced in the following section. The parametrization of a powertrain concept is represented by a set of design parameters $d$ which is shown in Table 1.

We use the genetic algorithm from the MATLAB toolbox (MathWorks) and define a mixed-integer optimization problem with the design parameter set as search space and the REI as objective function.

A specific combination of design parameter values is encoded as the genome of an individual, in which $N_{\text {ICE }}$ and $n_{\text {Transm }}$ are integers and all other parameters are real

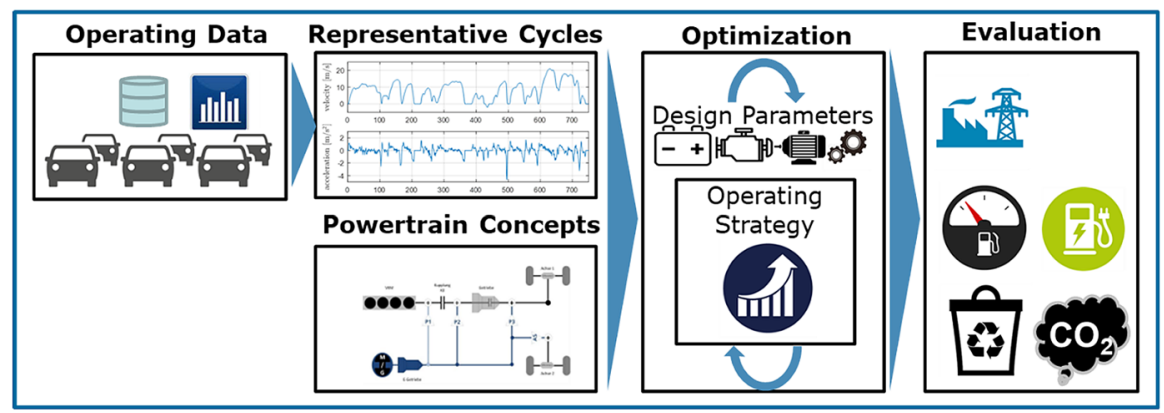

Fig. 1 Illustration of the optimization framework 
Table 1 Design parameter set $\boldsymbol{d}$ of the optimization process

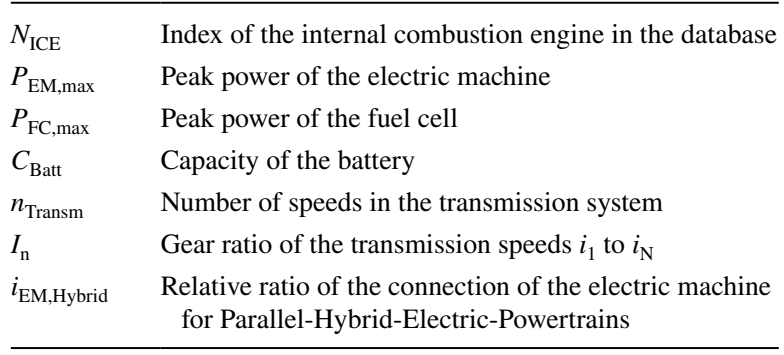

numbers. A starting population of individuals is then iteratively adapted through a rank-based selection of individuals which are evolved by mutation and crossover. The default mutation and crossover functions for a mixed-integer problem from the MATLAB toolbox are used and elitism is considered. The values of the design parameters are bounded by lower and upper thresholds and for individuals that do not meet the previously mentioned feasibility or design constraints, penalty terms are added to their fitness value. This way, it is ensured that the individual with the best fitness yields the lowest REI while still satisfying all constraints. As termination condition, we use a number of stall generations over which the relative change in the best fitness value is below a given function tolerance. The main hyperparameters of the genetic algorithm are summarized in Table 2.

\section{Driving profiles and parameter set for the evaluation}

In order to achieve a proper estimation of the REI for different powertrain concepts and for different driving profiles, real driving data for the specific driving profiles must be considered. In this study, the comparative evaluation of the REI is performed for three different driving profiles and the resulting differences in the REI and the powertrain parametrizations are discussed. The first driving profile (reference profile) shall offer good comprehensibility for the reader, which is why the well-known Artemis driving cycles for urban, rural and highway driving are used to describe the driving behaviour. The second driving profile is built based on recorded tracks from a pool-vehicle at the TU Darmstadt (pool-vehicle profile). The driving data consists of tracks from different drivers that use the car for business duties. Finally, the third driving profile is based on driving data recorded from an individual

Table 2 Main hyperparameters of the genetic algorithm used

\begin{tabular}{ll}
\hline Population size & 400 \\
Number of stall generations & 20 \\
Function tolerance & $10^{-5}$ \\
Crossover fraction & 0.8 \\
Elite count & 5 \\
Crossover function & Laplace crossover \\
Mutation function & Power mutation \\
\hline
\end{tabular}


employee of the TU Darmstadt (employee profile) in his personal car. It consists of all trips that the individual employee performed during the recording period.

Our two own driving profiles (pool-vehicle and employee profile) are based on recorded tracks, from which the occurrence frequency of vehicle states in the velocity-acceleration plane is calculated, as shown in Fig. 2 for the pool-vehicle. The driving profiles are further divided into sub profiles for different trip distances, since the trip distance has a significant impact on driving behaviour, as shown in Fig. 3 for the pool-vehicle profile. One example for the differences in the sub profiles is, that the occurrence frequency of high velocity increases significantly for higher trip distances due to the higher presence of highway driving. On the other hand, high accelerations or sportive driving at lower velocity bellow $100 \mathrm{~km} / \mathrm{h}$ occurs predominantly on shorter trips. Apparently, the drivers prefer more moderate driving within this velocity region on longer trips. Thus, different trip distances and thus different driving behaviour in the original data result in different energy related demands. Furthermore, the division into sub profiles is necessary for a precise depiction of hybrid powertrain concepts with two energy sources, since the consumption of the concepts depends, despite the driving-behaviour, on the distance of the tracks. Shorter tracks allow for an increased percentage of electrical driving compared to longer tracks. A hybrid concept might drive a short track completely electrically, but needs to use the combustion engine or fuel cell for longer tracks (even if the tracks have equal operating points) to achieve the desired range.

The optimization environment uses a backward facing vehicle simulation model (Sect. 5), to estimate the petrol, CNG, hydrogen and electric consumption for different parametrizations of a powertrain concept on given driving cycles. The driving cycles for the reference profile are given with the Artemis cycles, shown in Fig. 4. For our own two driving profiles, the cycles synthesis procedure (Esser et al. 2018) is used to generate representative driving cycles from the occurrence frequency distributions of the sub profiles. The synthetic driving

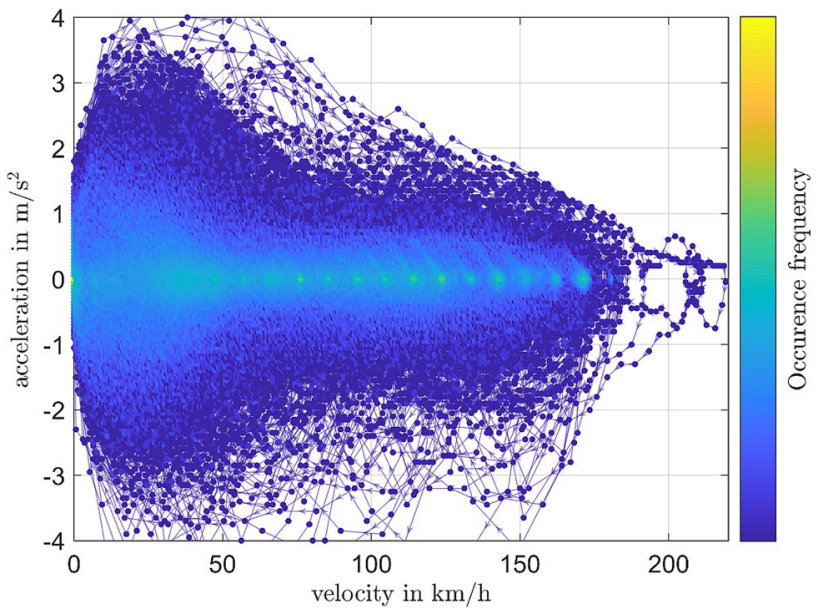

Fig. 2 Overall driving profile for the pool-vehicle 

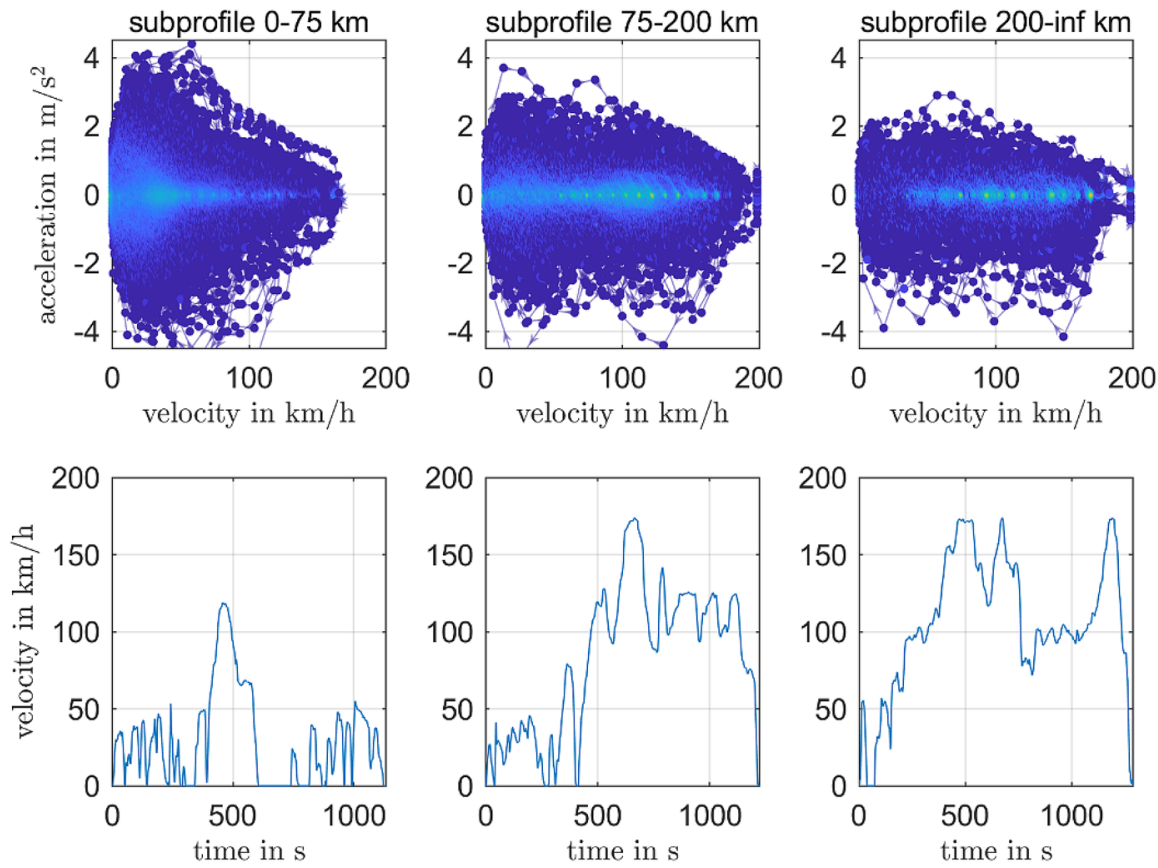

Fig. 3 Sub profiles of the pool-vehicle profile and the corresponding representative driving cycles for the optimization environment
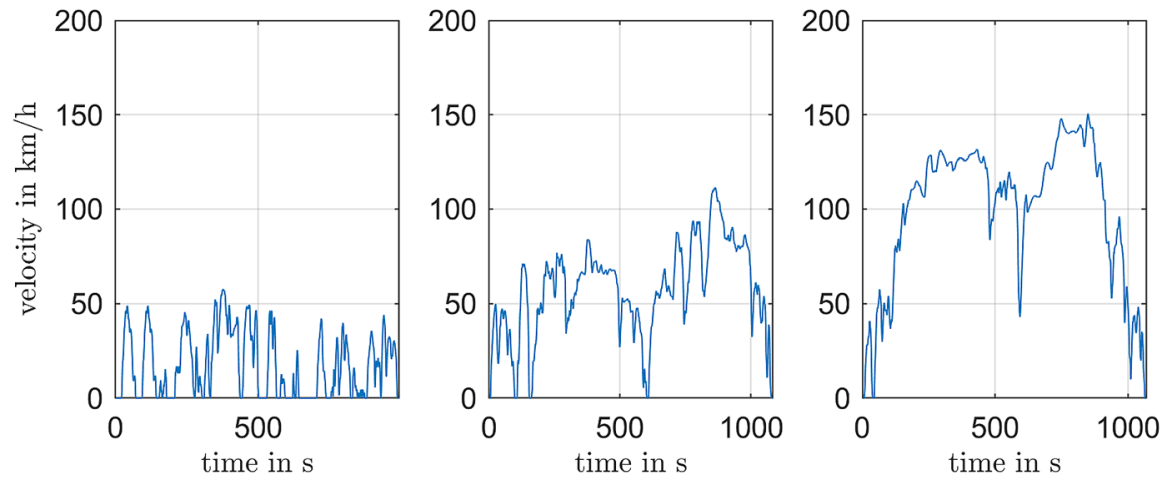

Fig. 4 The three Artemis driving cycles, that are used for the reference profile. From left to right: Artemis Urban, Artemis Rural, Artemis Highway (150 km/h version)

cycles match the sub profiles in statistic quantities, such as the normalized driving resistances or the mean value and variances of velocity as well as acceleration and compress the datasets significantly. Therefore, they are suited to calculate the consumptions of many different powertrain parametrizations with high efficiency within the optimization. 

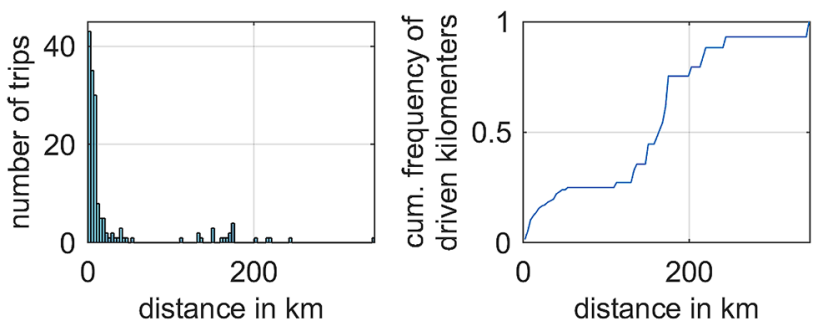

Fig. 5 distribution of trip distances for the pool-vehicle profile

Table 3 Chosen trip distances and weighting factors for the three driving profiles

\begin{tabular}{llcl}
\hline & Total recorded kilometres & $\begin{array}{l}\text { Chosen trip distances } \\
\text { in km }\end{array}$ & $\begin{array}{l}\text { Weighting } \\
\text { factor }(\%)\end{array}$ \\
\hline Reference profile & Artemis urban cycle & 60 & 71 \\
& Artemis rural cycle & 100 & 12 \\
& Artemis highway cycle $(150 \mathrm{~km} / \mathrm{h}$ & 200 & 8 \\
& version $)$ & 350 & 9 \\
Pool-vehicle profile & $4980 \mathrm{~km}$ & 60 & 25 \\
& & 150 & 50 \\
& & 225 & 18 \\
Employee profile & $2546 \mathrm{~km}$ & 350 & 7 \\
& & 60 & 41 \\
& & 100 & 15 \\
& 180 & 26 \\
& & 230 & 18 \\
& & 350 & $\sim 0$
\end{tabular}

For the reference profile, the trip distances and weighting factors were determined based on own assumptions for a typical user. In case of the further two driving profiles, they were calculated from the recorded tracks

Together, the sub profiles define the overall driving profile and are therefore weighted according to their percentage of the total driven distance. Within the optimization environment, the representative sub profile driving cycles are simulated for all powertrain concept parametrizations and the resulting consumptions are then weighted according to their percentage of total driven distance.

Figure 5 shows the distribution of trip distances for the pool-vehicle profile. The first sub profile which contains tracks from 0 to $75 \mathrm{~km}$ distance covers approximately $25 \%$ and the second sub profile with tracks from 75 to $200 \mathrm{~km}$ respectively $50 \%$ of the driven kilometres. The chosen trip distances and corresponding weighting factors for the three profiles are summarized in Table 3. For all three profiles, a maximum range of $350 \mathrm{~km}$ on the respective high-distance driving cycle will be required to enable long-range capability.

The three sub profiles of the employee profile and the synthesized driving cycles that are used within the optimization environment are shown in Fig. 6. 

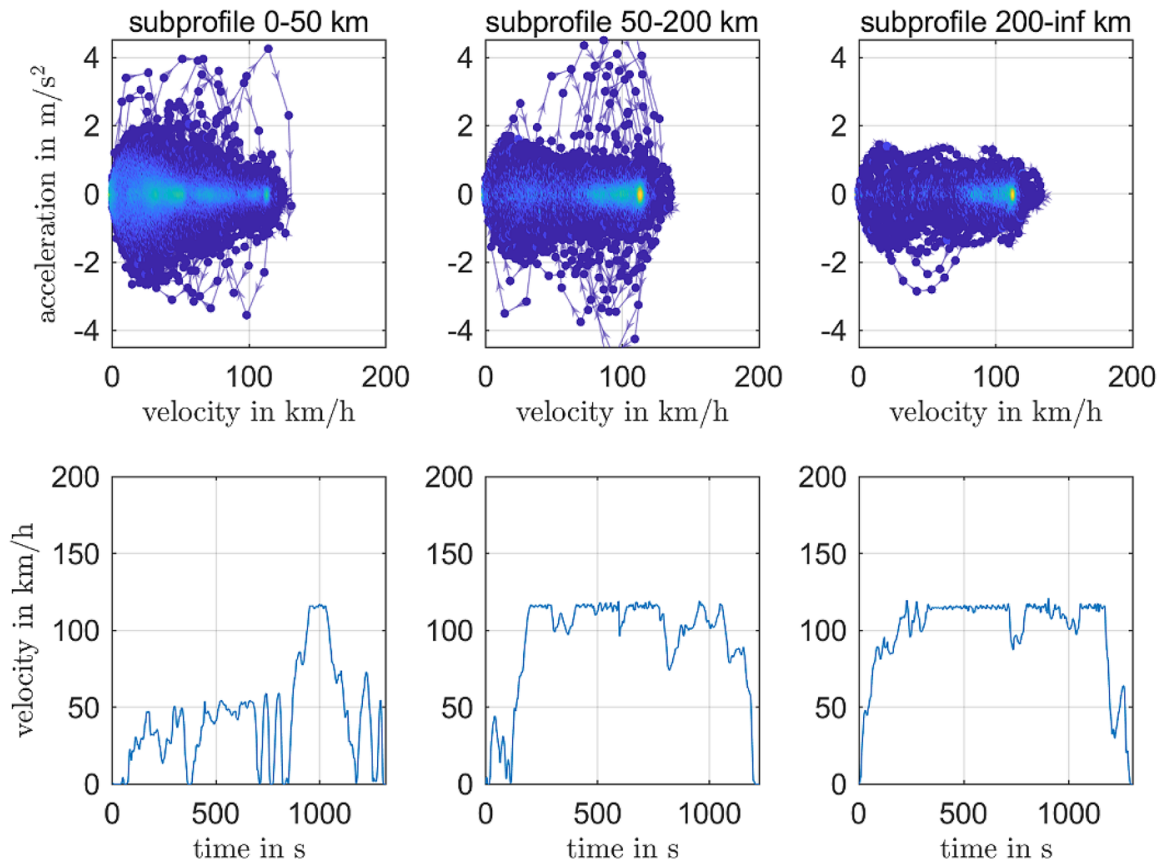

Fig. 6 Sub profiles of the employee profile and the corresponding representative driving cycles for the optimization environment

There are obvious differences in the driving behaviour between the pool-vehicle profile and the employee profile. The pool-vehicle profile (Fig. 3) shows, that the vehicle is driven more dynamic with higher accelerations and top speeds. Furthermore, there are various states at constant speed with a high frequency occurrence resulting from the use of the Adaptive Cruise Control (ACC) function in speed mode of the vehicle at different speeds. For the employee profile on the other hand, the ACC function is predominantly used at $120 \mathrm{~km} / \mathrm{h}$, corresponding to the preference of the individual driver. This dominant operating point can also be seen in the synthesized driving cycles for the long trip distances in Fig. 6.

Due to the significant differences in the driving profiles, different consumption estimations and thus different REI evaluations, our method lead to different REIoptimal powertrain parametrizations for each concept depending on the driving profile.

For the evaluation of the REI of different powertrain concept parametrizations, a parameter set is required to estimate the specific emissions of $\mathrm{CO}_{2}$-eq. over the entire life cycle of the vehicles. For the assessment in this study, the parameter set is meant to describe the boundary conditions in Germany in the year 2030 and a corresponding expected development from today's technology parameters is considered. The scenario parameters are summarized in Table 4. Within this study, we assume that the installed batteries achieve the desired lifetime without battery degradation or failure. Therefore, no second batteries are required 
Table 4 Summary of the scenario parameters with the highest impact on the REI

\begin{tabular}{ll}
\hline Parameter & Value \\
\hline Specific emissions of electric energy production & $400 \mathrm{~g} \mathrm{CO}_{2} / \mathrm{kWh}^{\mathrm{a}}$ \\
Energy density of the Battery & $126-170 \mathrm{Wh} / \mathrm{kg} \mathrm{dependent} \mathrm{on} \mathrm{battery} \mathrm{size}^{\mathrm{b}}$ \\
Depth of discharge for the Battery & $80-90 \%$ dependent on battery size \\
Emissions in battery production & $12.95 \mathrm{~kg} \mathrm{CO}_{2}$-eq./kg \\
Total mileage & $250,000 \mathrm{~km}^{\mathrm{e}}$ \\
\hline
\end{tabular}

The references are indicated with the footnotes

${ }^{a}$ Chosen value between Helms et al. (2016) and Wietschel et al. (2019)

${ }^{\mathrm{b}}$ Lower limit from Thielmann et al. (2013)

${ }^{\mathrm{c}}$ Lower limit from auto motor sport (2016), upper limit from BMW Group (2018)

${ }^{\mathrm{d}}$ Further improvements for 2030 from study of Peters and Weil (2018)

${ }^{\mathrm{e}}$ Annual mileage of diesel vehicles within Germany (statista 2019) combined with the mean lifetime of passenger vehicles in Germany (Plötz and Kühn 2013)

and the technology parameters stay constant. A second use of the batteries is not considered.

Additionally, further emission related parameters have to be taken into account, such as the specific emission factors for the production of different powertrain components, the emission factors for the supply chain of fuels and the emission factors for the end of life. As an example, we give details for the resulting emissions in the production of the powertrain components in case of the reference profile according to the optimal vehicle concept (see Fig. 11). Furthermore, the emissions in the supply chain of different fuels are quantified according to the values in Table 5.

\section{Vehicle simulation model}

A vehicle simulation model is integrated into the optimization framework to estimate the energy consumption of the different powertrain concepts. The model consists of two parts: a primary consumption model used to estimate the energy demand required for moving the vehicle and a secondary consumption model to estimate the energy demand for auxiliary systems. As shown in Jardin et al. (2019), the energy to temperate the passenger vehicle cabin strongly depends on the ambient temperature and has a significant influence on the overall vehicle consumption. Additionally,

Table 5 Emissions of $\mathrm{CO} 2$-eq. in the supply chain of relevant fuels

\begin{tabular}{ll}
\hline Emissions in fuel supply & $\mathrm{kg} \mathrm{CO}_{2}$-eq./kg \\
petrol-E10 (10\% Bioethanol) & $0.711^{\mathrm{a}}$ \\
CNG & $0.770^{\mathrm{b}}$ \\
Hydrogen & $15.37^{\mathrm{c}}$ \\
\hline
\end{tabular}

${ }^{\mathrm{a}}$ Edwards et al. (2014) and Helms et al. (2011)

${ }^{\mathrm{b}}$ Edwards et al. (2014)

${ }^{\mathrm{c}}$ Edwards et al. (2014) 


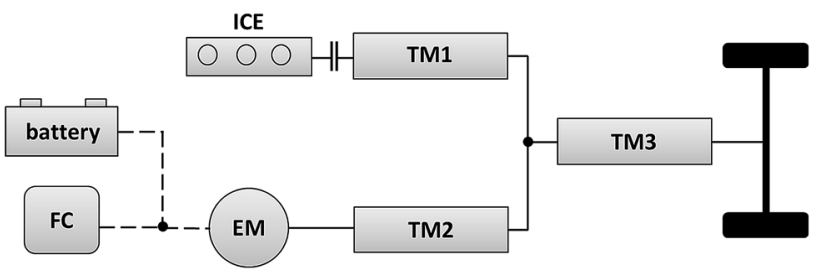

Fig. 7 Generic powertrain model: Single components can be omitted by binary encoding

Table 6 Encoding concepts through binary codes using the generic powertrain model

\begin{tabular}{lll}
\hline Concept & Description & $\begin{array}{l}\text { Binary encoding (ICE,E } \\
\text { M,FC,TM1,TM2,TM3,b } \\
\text { attery) }\end{array}$ \\
\hline ICEV-E10 & Conventional vehicle with petrol engine & $(1,0,0,1,0,0,0)$ \\
ICEV-CNG & Conventional vehicle with CNG engine & $(1,0,0,1,0,0,0)$ \\
BEV-1 & Battery electric vehicle with fixed gear ratio transmission & $(0,1,0,0,1,0,1)$ \\
BEV-2 & Battery electric vehicle with 2-speed transmission & $(0,1,0,0,1,0,1)$ \\
FCHEV & Fuel cell hybrid electric vehicle & $(0,1,1,0,1,0,1)$ \\
FCPHEV & Fuel cell plug-in hybrid electric vehicle & $(0,1,1,0,1,0,1)$ \\
PHEV-E10 & Plug-in hybrid (P2 configuration) with petrol engine & $(1,1,0,0,1,1,1)$ \\
PHEV-CNG & Plug-in hybrid (P2-configuration) with CNG engine & $(1,1,0,0,1,1,1)$ \\
\hline
\end{tabular}

different technologies are used for different powertrain concepts to satisfy this demand. For example, we assume that in case of a powertrain without an ICE, the energy for heating the cabin has to be supplied by a Positive Temperature Coefficient (PTC) thermistor and thus by the traction battery energy. For the results within this work, we use the model introduced in Jardin et al. (2019) to calculate the secondary energy demand which is calculated first and then considered in the energy management of the operating strategy inside the primary consumption model.

\subsection{Generic powertrain model}

The energy consumption of a powertrain variant depends on the respective driving cycle, the parametrization of the powertrain and the operating strategy. A generic powertrain model is derived to differentiate between multiple powertrain concepts by including or omitting single parts of the powertrain through a binary encoding, as shown in Fig. 7.

The major components of the powertrain modelled are the energy converters (Internal Combustion Engine ICE, Electric Machine EM and Fuel Cell FC), the (sub-)transmissions and the battery. The powertrain concepts and their respective powertrain encoding investigated in this work are shown in Table 6 . When the binary value of a specific component is zero, the component has no effects on the modelling of the respective powertrain. For instance, since the ICEV-E10 has no 
EM, only the consumption of the ICE is calculated and no emissions of the EM are estimated for production and end-of-life phases for this vehicle.

The primary consumption model is based upon a backward facing formulation of the longitudinal dynamics of the vehicle, assuming that the lateral and vertical dynamics only have a negligible effect on the consumption. Therefore no driver model is needed and it is assured that all vehicles exactly follow the driving cycle. With the driving cycle as input, a driving resistances equation estimates the traction demand at the wheels taking drag, rolling resistance and acceleration resistance into account. The traction demand is then met by multiple energy converters managed by the operating strategy, considering the efficiencies of energy converters and battery. The resulting operating points of the energy converters finally determine the respective energy consumption of the vehicle.

A map-based approach is used to represent the efficiency characteristics of the energy converters. Gridded efficiency data as a function of torque and speed from measurements and literature (An and Binder 2016, 2017) is linearly interpolated to give an estimation of the efficiency in each operating point. The efficiency of the FC is approximated by a 1-dimensional function of electric output power (Noreikat 2013). Transmissions and batteries are modelled with constant efficiencies, assuming that the sensitivity of the REI with regard to transmission and battery efficiencies is rather low.

\subsection{Operating strategy}

To preserve the comparability of different powertrain concepts, an operating strategy is used for all different powertrains in the same way. The operating strategy chooses the operating points of the energy converters by deciding on gear shifting and torque split between the ICE and the EM. A formulation of the Equivalent Consumption Minimization Strategy ECMS is applied that yields locally optimal operating points in each time step $t_{i}(\Delta t=1 \mathrm{~s})$ defined by the optimal torque split between the energy converters $t s^{*}\left(t_{i}\right)$ and gear mode $g m *\left(t_{i}\right)$, i.e. the respective transmission ratio, with respect to a virtual overall consumption that weights the electric power share by the balancing cost factor $s$. A cost function $J$ is defined, representing an equivalent fuel mass flow rate of electric and petrochemical power, which is minimized in every time step of the discretized driving cycle.

$$
\begin{aligned}
J\left(g m, t s, t_{i}\right)= & b_{e}\left(g m, t s, t_{i}\right) T_{I C E}\left(g m, t s, t_{i}\right) n_{I C E}\left(g m, t_{i}\right) \\
& +s \frac{1}{L H V} \frac{1}{\eta_{E M}\left(g m, t s, t_{i}\right) \eta_{\text {batt }}} T_{E M}\left(g m, t s, t_{i}\right) n_{E M}\left(g m, t_{i}\right) \\
t s^{*}\left(t_{i}\right), g m^{*}\left(t_{i}\right)= & \underset{t s, g m}{\arg \min } J\left(g m, t s, t_{i}\right)
\end{aligned}
$$

In the equations, $b_{\mathrm{e}}$ denotes the brake specific fuel consumption, LHV the lower heating value $T$ the torque, $n$ the rotational speed and $\eta$ the efficiency.

For concepts with a second energy source alongside the battery, the energy management of the operating strategy always assures that the battery is fully depleted at the end of the given trip distance by adjusting $s$ in a separate iteration loop. It 
is assumed that this results in the lowest REI possible for the concepts and hence ensures the comparability between different concepts. In the same fashion, the cost factor for electric powertrain concepts without plug-in functionality is determined so that they operate in charge sustaining mode. The trade-off between e.g. a higher battery capacity (and thus high emissions during battery production) and a higher usage of fuels in the operational phase of the vehicle with regard to the REI is dealt with in the optimization approach.

\subsection{Powertrain scaling approach}

Since the approach in this work optimizes the REI of the vehicles considering all phases of the life cycle, the sizing of the powertrain components is not only relevant for the energy consumption during operational phase, but also for production and end-of-life emissions. The parameters of the vehicle can be divided into two groups, dependent on whether or not they are a function of the design parameters. The latter group comprises parameters for the basic vehicle body that are identical for all vehicle concepts, e.g. drag coefficient, frontal area or base vehicle body mass. Efficiency maps, maximum power ratings of the energy converters and masses of the powertrain components depend on the design parameters and thus are affected by the vehicle optimization process.

In our approach, the sizing of the powertrain components is based on a parametrization of a limited number of design parameters. Especially the differences in the efficiency characteristics of the energy converters with respect to the design parameters, i.e. their power ratings, need to be considered. We mostly address this by applying a scaling approach to the efficiency maps of reference energy converters. With respect to the EM, a reference synchronous machine is defined (An and Binder 2016, 2017) and a torque based scaling method is applied to its efficiency map dependent on the peak power of the EM $P_{\mathrm{EM}, \max }$ which is part of the design parameter set $d$.

$$
\begin{aligned}
& \frac{T_{\text {EM,max }}}{T_{\text {ref,max }}}=\frac{P_{\text {EM,max }}}{P_{\text {ref,max }}} \\
& \eta_{E M}\left(T_{E M}, n_{E M}\right)=\eta_{\text {ref }}\left(T_{E M} \frac{P_{\text {ref,max }}}{P_{E M, \text { max }}}, n_{E M}\right)
\end{aligned}
$$

Concerning the FC, it is assumed that the efficiency as a function of FC power $P_{\mathrm{FC}}$ normed by its maximum power $P_{\mathrm{FC}, \max }$ remains the same with different rated powers, thus

$$
\eta_{\mathrm{FC}}\left(\mathrm{P}_{\mathrm{FC}}\right)=\eta_{\text {ref }}\left(P_{\mathrm{FC}} \frac{P_{\mathrm{FC}, \text { ref, max }}}{P_{\mathrm{FC}, \max }}\right)
$$

In order to avoid the scaling of ICE efficiency maps which is subject to large uncertainties, a database of different rated ICE powers is built up from which the optimizer can select a discrete ICE with its respective efficiency map by its index in the ICE database $N_{\text {ICE }}$. Due to the absence of a comprehensive database of CNG 
engines, we also use the efficiency maps of the petrol engines for $\mathrm{CNG}$, which possibly underestimates the higher efficiencies of a dedicated CNG engine.

As mentioned before, the masses of the vehicle components are key for estimating the emissions during production and end-of-life phases with regard to the design parameter set $\boldsymbol{d}$. For several components like transmissions and the battery, the masses are calculated based on empirical correlations as a function of the design parameters. For the remaining components, nonlinear regression curves are derived to obtain a functional relationship between the component masses and the design parameters.

\subsection{Emissions modelling}

The emissions during production and end-of-life phases are modelled as linear functions of the vehicle component masses $m_{j}$.

$$
G_{j}(\boldsymbol{d})=c_{j} m_{j}(\boldsymbol{d})
$$

with $j$ indexing the respective component, $G$ denoting the emissions and $c$ the emission coefficient.

Emissions during the operational phase consist of the direct tailpipe emissions and the emissions of the fuel and electricity supply.

Several feedback effects concerning the parameter scaling arise from the modelling approach, for example regarding the vehicle range. To increase the range of a BEV, the capacity of the battery can be increased, which in turn increases the vehicle mass and may lead to a higher energy consumption, reducing the range of the vehicle. These feedback effects are covered and resolved by the applied genetic algorithm.

\section{Results}

Within this section, the results of the comparative assessment of the REI of the different powertrain concepts for the investigated driving profiles are presented. For all three profiles a range of $350 \mathrm{~km}$ is required to achieve long-range capability. For the reference profile, a detailed description of the optimized parametrizations and the operating behaviour of a chosen vehicle is given. For the further profiles, only the final results are shown.

\subsection{Results for the reference profile}

In Table 7, the resulting parametrizations of the different powertrain concepts are shown. As explained in Sect. 3, the parametrizations enable a minimum REI, while fulfilling the design constraints.

The BEV class concepts require an installed gross battery capacity of $82-84 \mathrm{kWh}$ dependent on the powertrain concept to reach the desired range on the highway cycle. Due to the weight of the battery, the total mass of these vehicles is 


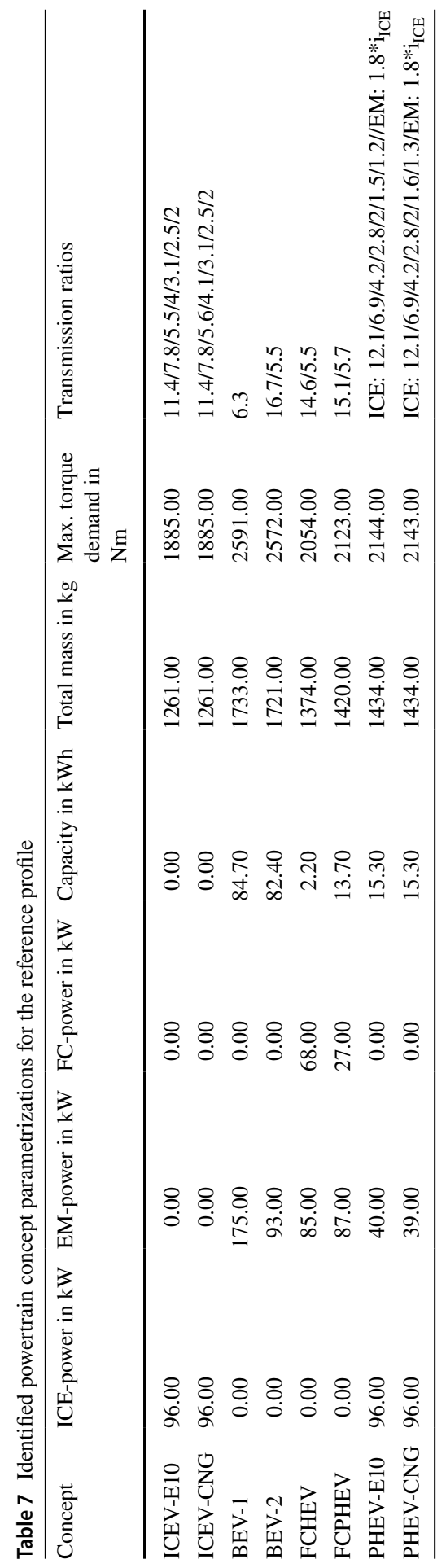


significantly larger compared to the other concepts. Because the BEV-1 concept is not equipped with a shiftable transmission, a high powered EM is necessary to fulfil the demanded launch torque with a rather low transmission ratio that enables to reach the required maximum velocity. The BEV-2 concept on the other hand can fulfil the design constraints with a lower power rating (based on the scaling of the maximum torque), using a high transmission ratio to enable the launch torque and a lower ratio to reach the maximum velocity. The downsized machine and the option to choose operating points result in higher efficiency for the BEV-2, and thus a decreased electric consumption as shown in Fig. 8.

Regarding the FCEV class, one concept with (FCPHEV) and one without (FCHEV) the possibility of external charging are considered. The optimized FCHEV is characterized by a small battery capacity and a high power FC. The FCPHEV, on the other hand, has a higher battery capacity and needs less power from the FC to satisfy the design constraints. It can drive short distances purely electric, but uses the FC on longer trip distances.

For the PHEV class, the PHEV-E10 and PHEV-CNG are parametrized in almost similar manner, see Table 7.

As an example for the modelling within the optimization environment, the operating behaviour of the PHEV-E10 on the Artemis highway cycle on a trip distance of $350 \mathrm{~km}$ is shown in Fig. 9. The operating points of the traction machines and the gears are chosen depending on the given driving cycle, the specific parametrization and the available battery electric energy. The driving behaviour is trimmed, such that the available battery capacity is depleted at the end of the trip. The operating strategy enables to drive solely with the EM or the ICE or in combination to perform load point shifts (boosting and shifting). Based on the consumption orientated operating strategy, presented in Sect. 5, the consumption of electric energy, petrol, $\mathrm{CNG}$ or hydrogen are calculated for each parametrization of all powertrain concepts within the optimization environment.

Finally, the resulting REI for each powertrain concept is shown in Fig. 10. First, it can be seen that conventional vehicles result in the highest REI compared to the electrified powertrain concepts for the reference profile, while the use of CNG is beneficial to improve the REI within the ICEV class because the specific

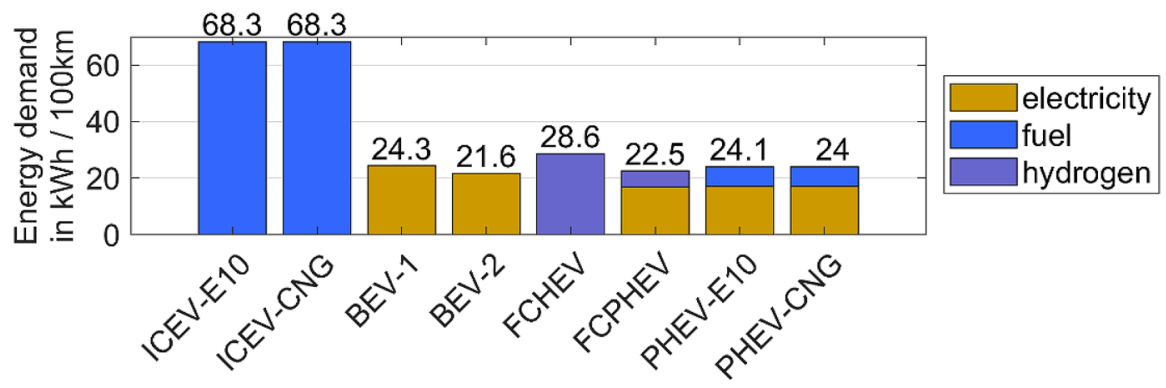

Fig. 8 Electricity, fuel and hydrogen consumption of all powertrain concepts in $\mathrm{kWh} / 100 \mathrm{~km}$ for the reference profile (1 L petrol-E10 corresponds $8.95 \mathrm{kWh}, 1 \mathrm{~kg} \mathrm{H}$ corresponds to $33.42 \mathrm{kWh}, 1 \mathrm{~kg}$ CNG corresponds to $12.83 \mathrm{kWh}$ ) 

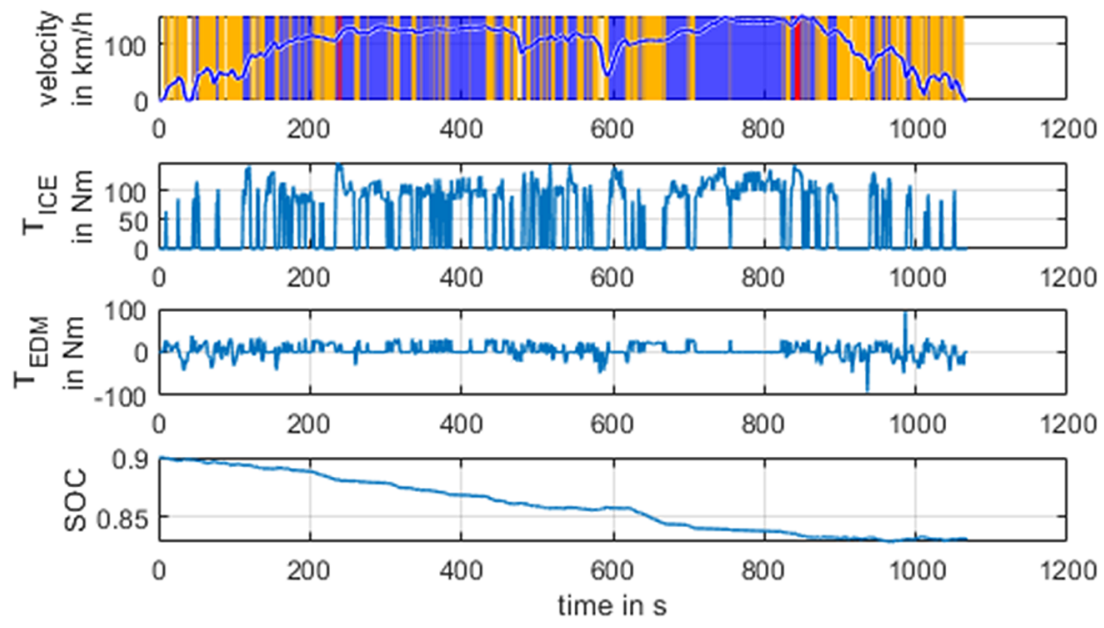

(a)

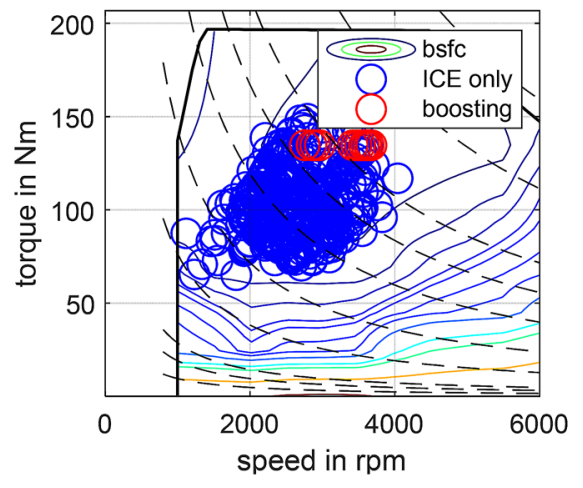

(b)

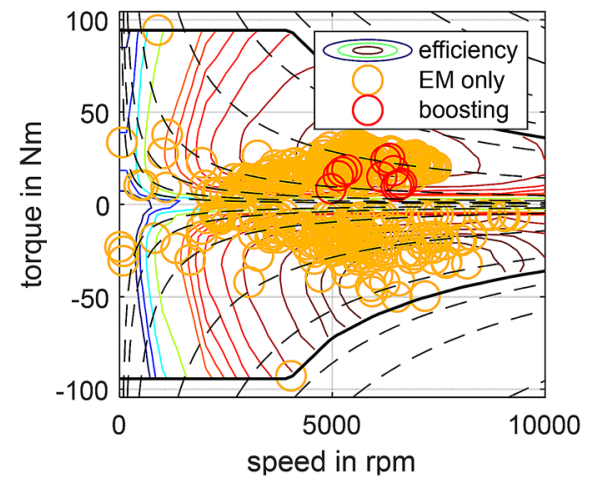

(c)

Fig. 9 Exemplary operating behavior within the vehicle simulation model of the PHEV-E10 on the highway cycle of the reference profile. Subfigure a shows the driving cycle and the time-dependent motor torques and state of charge of the battery. The colors indicate operating modes like purely electrical driving, combustion engine driving or hybrid modes like boosting for the highest traction power demands. Subfigure b shows the corresponding operating points of the ICE in the map of brake specific fuel consumption (bsfc). Subfigure $\mathbf{c}$ shows the operating points of the EM

emissions per chemically stored energy are lower for CNG. The BEV class concepts outperform the conventional concepts. The production of the BEV concepts lead to significantly higher emissions, especially due to the battery production. However, the overall high efficiency of the EMs, combined with the assumption of reduced specific emissions during the energy production in 2030, lead to an overall reduced REI. Within the considered concepts of the BEV class, the twospeed BEV (BEV-2) shows the best results. 


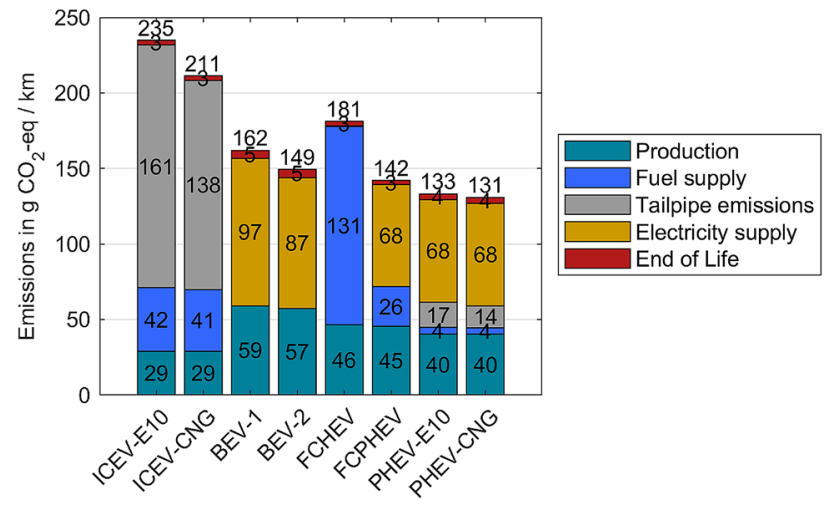

Fig. 10 Optimized REI for the powertrain concepts on the reference profile

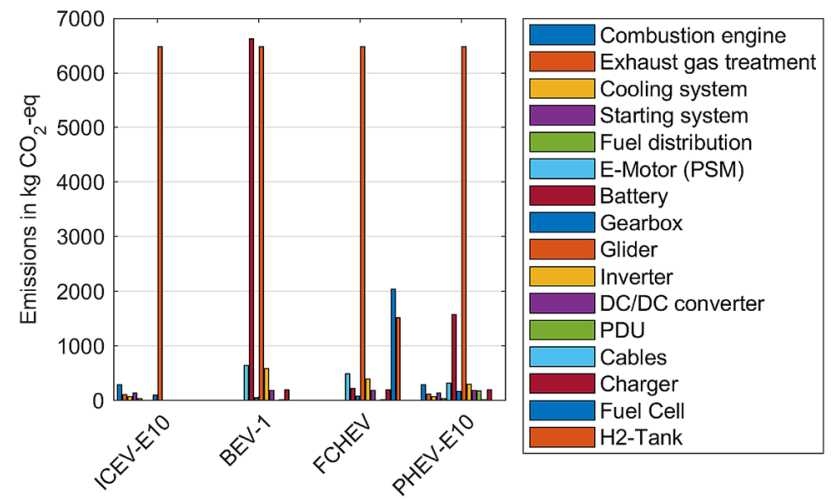

Fig. 11 Emissions of $\mathrm{CO} 2$-eq. during the production of the vehicle components

Within the FCEV class, the plug-in concept performs significantly better. There are two main reasons for this. First, the specific emissions in the supply of hydrogen are rather high (see Table 5) and the FCPHEV uses less hydrogen, since it has a plug-in possibility. Second, the FC shows a lower efficiency compared to the supply of electric energy via the battery. While the FCHEV leads to a worse REI compared to the BEV class, the FCPHEV shows an improvement.

The PHEV class concepts perform best for the reference profile. The installed battery capacity of around $15 \mathrm{kWh}$ is sufficient to enable a high percentage of purely electric driving, reducing the consumption of fuel, as shown in Fig. 8. Due to the moderate weight increase of the PHEV vehicles, the shiftable transmission and the downsizing of the EM lead to an efficient purely electric driving. For this assessment, it is assumed that the vehicles are charged prior to each trip, further reducing the fuel demand. In case of different usage behaviour and non-regular 
charging, the resulting REI would increase. The benefit of using CNG instead of petrol as fuel is shown again by the results of the PHEVs.

Further details about the production emission modelling of the powertrain components are given for one concept of each powertrain class in Fig. 11. The component weights and the resulting emissions in the production phase are estimated for each powertrain parametrization using scaling approaches (as explained in Sect. 5). Most significant impacts are due to the batteries with high capacity, the glider, the EM and power electronics as well as the hydrogen tank and the fuel cell.

\subsection{Results for the pool vehicle profile}

As shown in Sect. 4, the pool-vehicle is driven with high accelerations and top speeds. The specific driving profile results in a differing optimal parametrization of the powertrain concepts, summarized in Table 8. Overall, higher traction powers (than for the reference profile) are preferred for all concepts due to the more dynamic driving.

In case of the ICEV class concepts, a higher powered ICE is even required. Despite the more dynamic driving behaviour, the distance-related fuel consumption is significantly decreased compared to the reference profile (see Figs. 12 vs. 8). The reason for this is the much lower occurrence of low-efficient city driving with frequent acceleration and deceleration events, as summarized in Table 3, for which the ICEV concepts are disadvantageous.

The required battery capacity of the BEV concepts ranges from 91 to $94 \mathrm{kWh}$, which is higher compared to the reference profile, and the electric energy consumption is increased as well. As before, the two-speed BEV-2 concept leads to a significant downsizing effect of the EM and to a reduced consumption, which again enables a reduced battery capacity.

The PHEV concepts are equipped with a much larger battery capacity and a higher powered EM compared to the reference profile, which enables a high percentage of pure electric driving and frequent boosting with both energy converters on the dynamic driving profile. Interestingly, the PHEV-CNG concept is equipped with a slightly smaller battery capacity and slightly less electric power, which leads to a slight shift towards a higher use of fuel, due to the benefit of CNG over petrol considering $\mathrm{CO}_{2}$ emissions.

In Fig. 13, the resulting REI of all powertrain concepts for the pool-vehicle profile are shown. Compared to the reference profile, the REI of all powertrain concepts is increased except for the ICEV class, which is due to the decreased significance of city driving for this profile. As for the reference profile, the BEV concepts show lower REI compared to the ICEV concepts in 2030, even though the estimated benefit is significantly reduced for the pool-vehicle profile.

Regarding the vehicles of the FCEV class, the results differ significantly again. The FCPHEV profits from the capability to charge external electricity and performs better than the BEV concepts. The FCHEV on the other hand leads to the worst results of the considered concepts due to the high emissions in the supply of hydrogen (Table 5). 


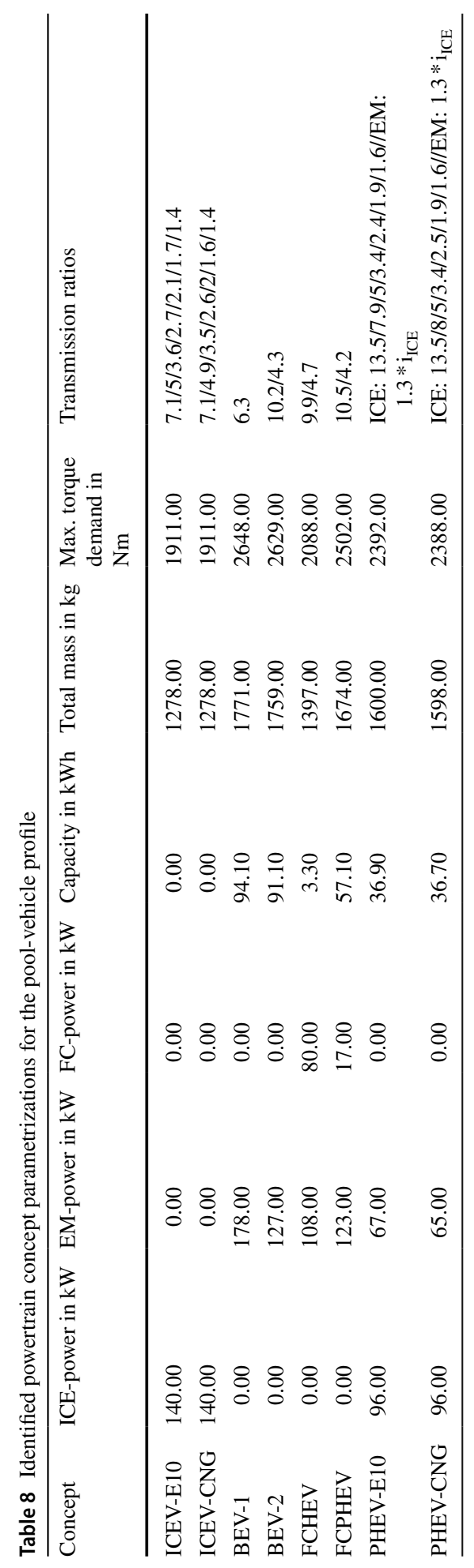




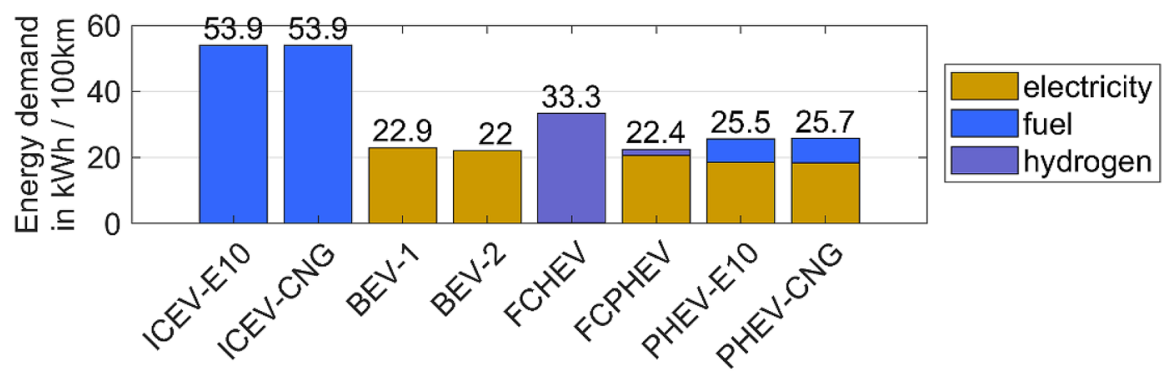

Fig. 12 Electricity, fuel and hydrogen consumption of all powertrain concepts in $\mathrm{kWh} / 100 \mathrm{~km}$ for the pool-vehicle profile. (1 L petrol-E10 corresponds $8.95 \mathrm{kWh}, 1 \mathrm{~kg} \mathrm{H}$ corresponds to $33.42 \mathrm{kWh}, 1 \mathrm{~kg}$ CNG corresponds to $12.83 \mathrm{kWh}$ )

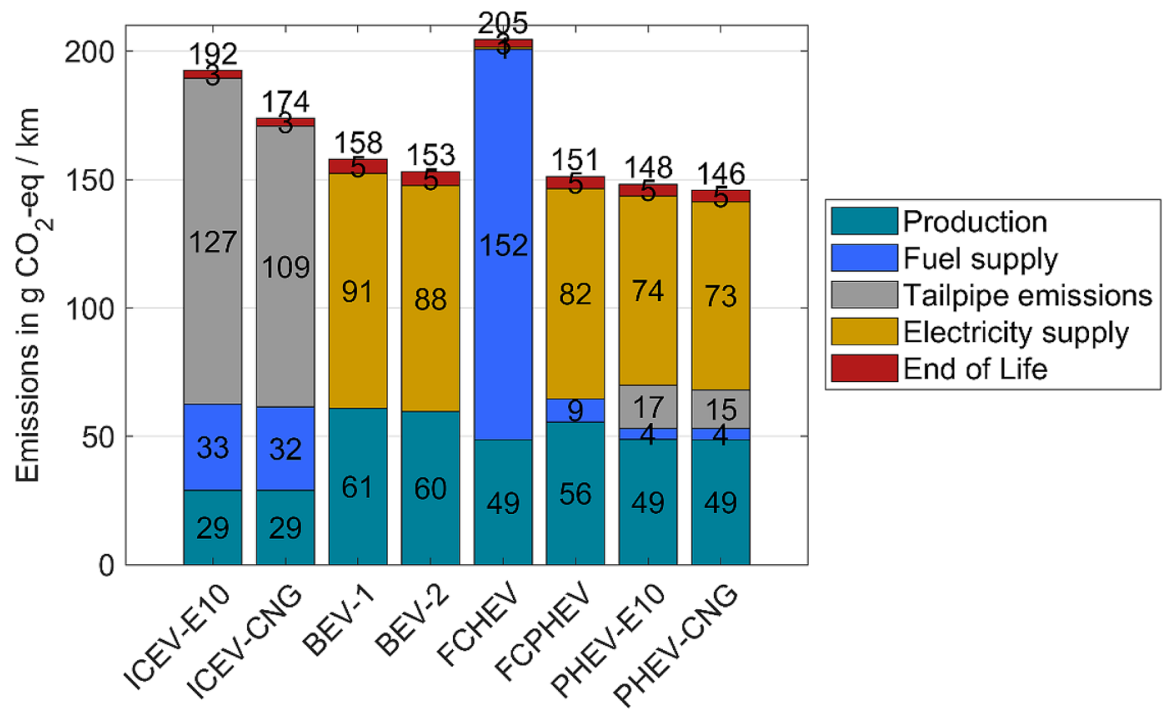

Fig. 13 Optimized REI for the powertrain concepts on the reference profile

The PHEV concepts perform best for the pool-vehicle profile. The downsized EM and the lower overall weight result in more efficient pure electric driving compared to the BEV concepts. The battery capacity of around $37 \mathrm{kWh}$ provides enough energy to achieve a high electric driving percentage, beneficial for the REI.

\subsection{Results for the employee profile}

The employee profile is characterized by efficiency oriented and defensive driving (see Sect. 4). During highway driving, an ACC system in speed mode was applied frequently to drive at a constant speed of $120 \mathrm{~km} / \mathrm{h}$. Higher velocities were completely avoided. The resulting parametrizations of the optimized powertrain concepts are summarized in Table 9. 


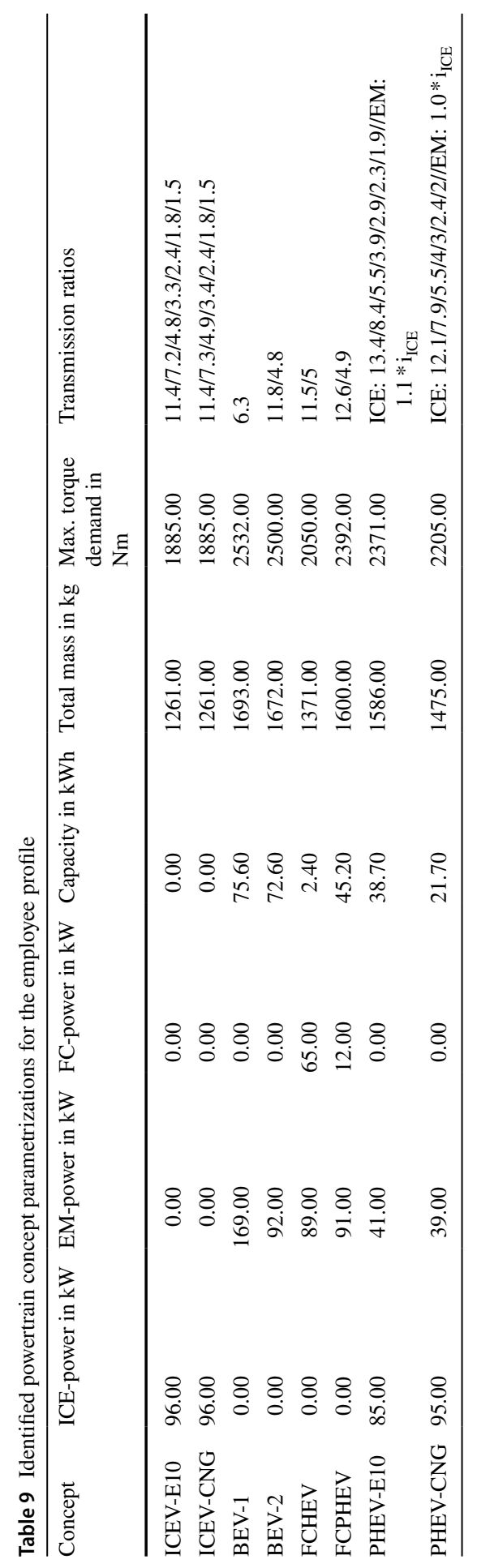


The required gross battery capacity of the BEV concepts is reduced to 72 respectively $75 \mathrm{kWh}$, because of the beneficial driving behaviour. Again, the potential downsizing effect for the BEV-2 compared to the BEV-1 can be observed.

The installed total traction powers of all concepts are similar to the parametrizations in the reference profile. For those two profiles, the maximum power demand is due to the design constraints and not the driving profile, leading to similar critical requirements. Because the battery capacities and the total vehicle mass are smaller for the employee profile, the necessary installed traction power is even slightly lower compared to the reference profile.

There is an interesting difference in the design of the PHEV-E10 and PHEVCNG. The battery capacity and EM power of the PHEV-CNG are lower, leading to an increased use of the ICE. The increased energy demand, shown in Fig. 14, is a result of the optimization regarding REI. If the objective would have been to minimize the total energy demand, a parametrization with a higher battery capacity would have been identified.

The results of the minimum REI optimized variants for each powertrain concept are shown in Fig. 15. Due to the efficiency orientated driving, the resulting REI is lower for all concepts, compared to the other driving profiles.

Within the classes, equal conclusions as for the other profiles can be drawn. A two-speed BEV-2 yields greater potential compared to fixed-speed BEV-1. A fuel cell vehicle should be designed as a plug-in vehicle when trying to minimize the ecological impact. The use of CNG is again shown to be beneficial for ICEV and PHEV concepts.

The PHEV concepts show the lowest REI values for the employee profile, followed closely by the FCPHEV concept.

\subsection{Comparison of the driving profiles}

In Table 10 the resulting REIs for the optimized powertrain concepts are shown for the three investigated driving profiles. Furthermore, the reduction of the REI compared to the ICEV-O in \% and the span of results are summarized.

The BEV concepts can lead to a mean reduction of the REI of $20.5-24.5 \%$ for long-range capable vehicles compared to a conventional ICEV on the investigated driving profiles. In the class of FC concepts, the results are highly sensitive to an

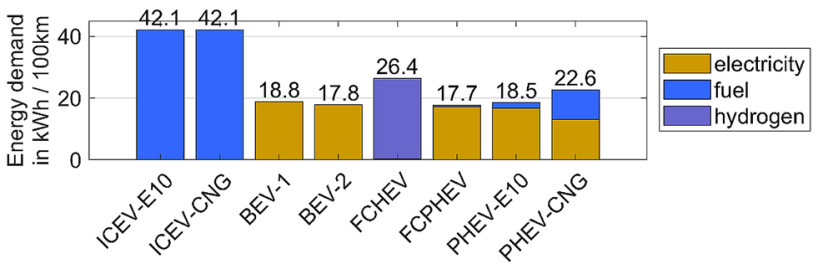

Fig. 14 Electricity, fuel and hydrogen consumption of all powertrain concepts in $\mathrm{kWh} / 100 \mathrm{~km}$ for the pool-vehicle profile. (1 L petrol-E10 corresponds $8.95 \mathrm{kWh}, 1 \mathrm{~kg} \mathrm{H}$ corresponds to $33.42 \mathrm{kWh}, 1 \mathrm{~kg}$ CNG corresponds to $12.83 \mathrm{kWh}$ ) 


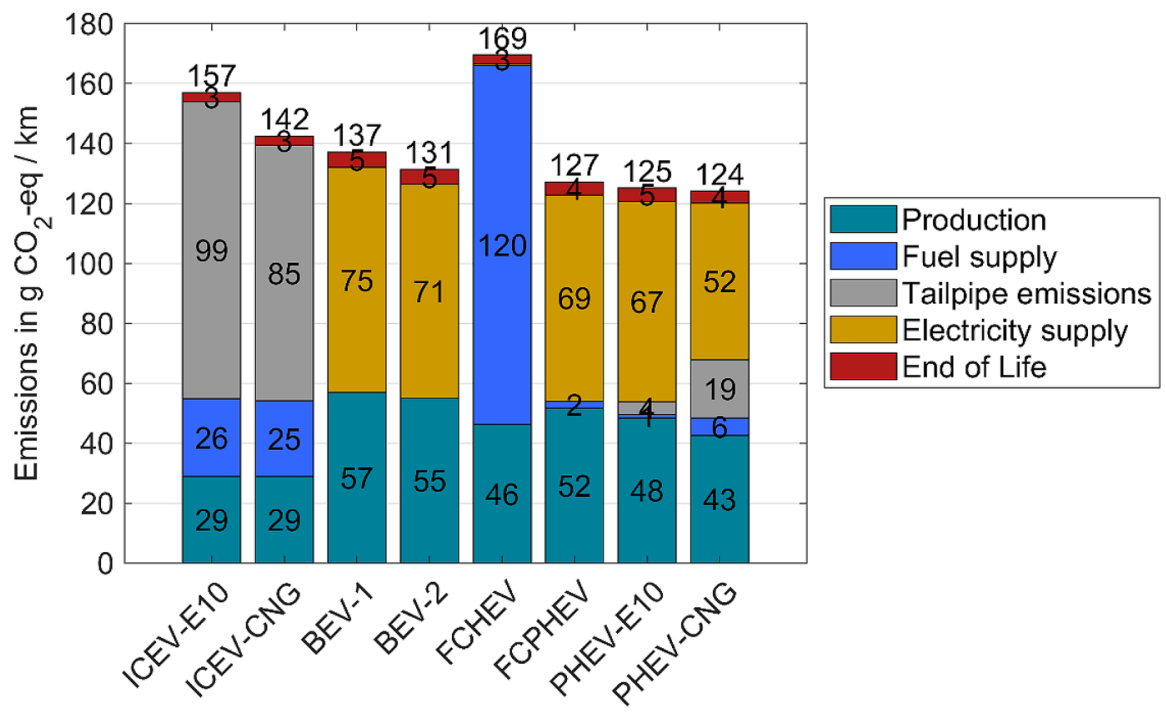

Fig. 15 Optimized REI for the powertrain concepts on the reference profile

Table 10 Comparison of the REI values $\left(\mathrm{gCO}_{2}\right.$-eq. $\left./ \mathrm{km}\right)$ for chosen powertrain concepts on the three investigated driving profiles

\begin{tabular}{|c|c|c|c|c|c|c|c|c|}
\hline REI in $\mathrm{g} \mathrm{CO}_{2} / \mathrm{km}$ & ICEV-E10 & ICEV-CNG & BEV-1 & BEV-2 & FCHEV & FCPHEV & PHEV-E10 & PHEV-CNG \\
\hline $\begin{array}{l}\text { Reference } \\
\text { profile }\end{array}$ & 235 & 211 & 162 & 149 & 181 & 142 & 133 & 131 \\
\hline $\begin{array}{l}\text { reduction to } \\
\text { ICEV-E10 in \% }\end{array}$ & & $10.2 \%$ & $31.1 \%$ & $36.6 \%$ & $23.0 \%$ & $39.6 \%$ & $43.4 \%$ & $44.3 \%$ \\
\hline $\begin{array}{l}\text { Pool vehicle } \\
\text { profile }\end{array}$ & 192 & 174 & 158 & 153 & 205 & 151 & 148 & 146 \\
\hline $\begin{array}{l}\text { reduction to } \\
\text { ICEV-E10 in \% }\end{array}$ & & $9.4 \%$ & $17.7 \%$ & $20.3 \%$ & $-6.8 \%$ & $21.4 \%$ & $22.9 \%$ & $24.0 \%$ \\
\hline $\begin{array}{l}\text { Employee } \\
\text { profile }\end{array}$ & 157 & 142 & 137 & 131 & 170 & 127 & 125 & 124 \\
\hline $\begin{array}{l}\text { reduction to } \\
\text { ICEV-E10 in \% }\end{array}$ & & $9.6 \%$ & $12.7 \%$ & $16.6 \%$ & $-8.3 \%$ & $19.1 \%$ & $20.4 \%$ & $21.0 \%$ \\
\hline $\begin{array}{l}\text { mean } \\
\text { reduction to } \\
\text { ICEV-E10 in \% }\end{array}$ & & $9.7 \%$ & $20.5 \%$ & $24.5 \%$ & $2.6 \%$ & $26.7 \%$ & $28.9 \%$ & $29.7 \%$ \\
\hline span & 78 & 69 & 25 & 22 & 35 & 24 & 23 & 22 \\
\hline
\end{tabular}

existing plug-in functionality. The REI of the FCHEV is strongly dependent on the respective driving profile. It achieves a reduced REI of $23 \%$ compared to the ICEV-E10 in the reference profile, but performs worse in the other two driving profiles. Overall, a slight mean reduction of the REI compared to the ICEV-E10 is enabled. The FCPHEV, on the other hand, achieves a reduction in all of the driving profiles, leading to a mean reduction of $26.7 \%$. Both concepts offer further potential if the emissions in the supply of hydrogen can be further reduced. 
The PHEV concepts achieve the highest potential on all investigated driving profiles and can reduce the REI by $28.9-29.7 \%$.

The span of the results of the three profiles indicates the sensitivity of the REI of powertrain concepts regarding different driving profiles. As can be seen, the span value of the ICEV concepts is significantly higher than the span values of the remaining concepts. The BEV-2, the FCPHEV and the PHEV class concepts show similar span values of 22-24 $\mathrm{CO}_{2}$-eq. $/ \mathrm{km}$. Furthermore, the span of the REI values shows that the driving profile is of high relevance for the resulting emissions. For this reason, apart from the identification of REI-optimal powertrains, further research on the efficient control of the vehicle's longitudinal dynamics should be carried out.

Overall, the FCPHEV and the PHEV concepts do not only show low REI values, the results are also less sensitive regarding different driving profiles. The beneficial results for these concepts, determined by this study, can only be achieved if the vehicles are regularly charged such that the available battery capacity can be used efficiently.

\section{Summary and conclusions}

In this work, we present a method aiming for an unbiased comparison of the ecological impact of different vehicle powertrain concepts based on a holistic optimization framework.

Present studies mostly refer to existing series production vehicles when performing a comparison of the ecological impact of different powertrain concepts, thus only determining the ecological impact of the respective vehicle and not the powertrain concept. We argue that in order to obtain an unbiased comparison of the powertrain concepts, the parametrization of the powertrain must be optimized to yield a minimum ecological impact before comparison. To address this, we created an optimization framework using a genetic algorithm that determines the optimal powertrain parametrization under given design constraints and for specific driving profiles. The objective function of the optimization is defined to be the Real Ecological Impact (REI) of a vehicle, which refers to the GHG emissions of the vehicle emitted over the entire life cycle when considering real driving profiles.

The real driving profiles that consist of data recorded during vehicle usage are compressed into driving cycles by a cycle synthesis process for an efficient evaluation of the energy consumption inside the optimization framework. A vehicle simulation with a generic powertrain model is used for energy consumption estimation which enables the simulation of different powertrain concepts and which is able to incorporate the effects of different powertrain parametrizations on the consumption. In addition to the GHG emissions during operational phase, the emissions of production and end-of-life phases are calculated as a function of the design parameter set, i.e. the powertrain parametrization.

In this work, we analyzed 8 different powertrain concepts comprising vehicles with different energy converters (ICE/EM/FC) and different energy sources (petrol, CNG, battery, hydrogen) on 3 different driving profiles for a set of predicted 
technological boundary parameters for 2030 like the specific emissions of energy production. Our results show that the underlying driving profile has a significant impact on the REI of the powertrain concepts, demonstrating the necessity of a method that evaluates the powertrain concept based on real driving data. In general, concepts with plug-in functionality, i.e. external battery charging, show a smaller REI throughout all of the driving profiles. The optimization approach especially reveals the potential of hybrid vehicles, since both energy converters are sized in a way that takes advantage of their synergetic use, enabling the downsizing of both energy converters - depending on the driving profile. Therefore, the PHEV concepts achieve the lowest REI in all of the investigated driving profiles. When looking at the sensitivity of the powertrain concepts in respect to the driving profile, the BEV and PHEV concepts are least sensitive to different driving profiles. It should be noted though that in this work, the demanded driving range is the same throughout all driving profiles, therefore the sensitivity of the REI regarding the range, which is generally very high for BEV, as it is shown in previous studies (Esser et al. 2019), is not considered here.

The generic method we present here also enables arbitrary further investigations with different powertrain concepts and driving profiles while always ensuring the comparability between different powertrain concepts.

Acknowledgements Open Access funding provided by Projekt DEAL.

Open Access This article is licensed under a Creative Commons Attribution 4.0 International License, which permits use, sharing, adaptation, distribution and reproduction in any medium or format, as long as you give appropriate credit to the original author(s) and the source, provide a link to the Creative Commons licence, and indicate if changes were made. The images or other third party material in this article are included in the article's Creative Commons licence, unless indicated otherwise in a credit line to the material. If material is not included in the article's Creative Commons licence and your intended use is not permitted by statutory regulation or exceeds the permitted use, you will need to obtain permission directly from the copyright holder. To view a copy of this licence, visit http://creativecommons.org/licen ses/by/4.0/.

\section{References}

An J, Binder A (2016) Permanent magnet synchronous machine design for hybrid electric cars with double e-motor and range extender. Elektrotech Inftech 133(2):65-72. https://doi.org/10.1007/s0050 2-016-0397-7

An J, Binder A (2017) Operation strategy with thermal management of E-machines in pure electric driving mode for twin-drive-transmission (DE-REX). In: 2017 IEEE vehicle power and propulsion conference (VPPC). Proceedings: 14-17 Dec 2017, Belfort, France. 2017 IEEE Vehicle Power and Propulsion Conference (VPPC). Belfort, 11 Dec 2017-14 Dec 2017. IEEE Vehicle Power and Propulsion Conference; Institute of Electrical and Electronics Engineers; VPPC. IEEE, Piscataway, NJ, pp 1-6. Accessed on 19 Dec 2018

Auto Motor Sport (2016) Technische Daten BMW i3 (94 Ah). Accessed on 25 Sept 2019

BMW Group (2018) Technische Daten BMW i3 (120 Ah). https://www.press.bmwgroup.com/deutschlan d/article/detail/T0285608DE/technische-daten-bmw-i3-120-ah-und-bmw-i3s-120-ah-gueltig-ab11/2018? language $=$ de. Accessed on 25 Sept 2019 
Ebbesen S, Dönitz C, Guzzella L (2012) Particle swarm optimisation for hybrid electric drive-train sizing. Int J Veh Des 58(2/3/4):181. https://doi.org/10.1504/ijvd.2012.047382

Edwards R, Godwin S, Hamje H, Hass H, Krasenbrink A, Larivé J-F et al (2014) Well-to-wheels report version 4.a. JEC well-to-wheels analysis: well-to-wheels analysis of future automotive fuels and powertrains in the European context. Publications Office of the European Union, Luxembourg (EUR, Scientific and technical research series, 26236)

Eghtessad M (2014) Optimale Antriebsstrangkonfigurationen für Elektrofahrzeuge. Dissertation. Aachen: Shaker (Schriftenreihe des Instituts für Fahrzeugtechnik, TU Braunschweig, 35)

Eghtessad M, Meier T, Rinderknecht S, Küçükay F (2015) Antriebsstrangoptimierung von Elektrofahrzeugen. ATZ Automobiltech Z 117(9):78-85. https://doi.org/10.1007/s35148-015-0089-3

EPA (2019) Understanding Global warming potentials. United States Environmental Protection Agency. https://www.epa.gov/ghgemissions/understanding-global-warming-potentials. Accessed on 25 Sept 2019

Esser A, Zeller M, Foulard S, Rinderknecht S (2018) Stochastic synthesis of representative and multidimensional driving cycles. SAE Int J Alt Power 7(3):263-272. https://doi.org/10.4271/2018-01-0095

Esser A, Schleiffer J-E, Eichenlaub T, Rinderknecht S (2019) Development of an optimization framework for the comparative evaluation of the ecoimpact of powertrain concepts. In: 19. Internationaler VDI-Kongress "Dritev - Getriebe in Fahrzeugen”, Bonn, 10.-11. Juli 2019, In: VDI-Berichte, 2354. ISBN 978-3-18-092354-3

Helms et al (2016) Weiterentwicklung und vertiefte Analyse der Umweltbilanz von Elektrofahrzeugen. Accessed on 27 April 2018

Helms H, Jöhrens J, Hanusch J, Höpfner U, Lambrecht U, Pehnt M (2011) UMBRELA. Wissenschaftlicher Grundlagenbericht gefördert durch das Bundesministerium für Umwelt, Naturschutz und Reaktorsicherheit (BMU). Accessed on 16 May 2018

IPCC (2014) Climate change 2014-synthesis report. In: Core Writing Team, Pachauri RK, Meyer LA (eds.) Contribution of working groups I, II and III to the fifth assessment report of the intergovernmental panel on climate change. IPCC, Geneva, Switzerland, $151 \mathrm{pp}$. Edited by IPCC

ISE, Fraunhofer (2019) Treibhausgas-Emissionen für Batterie- und Brennstoffzellenfahrzeuge mit Reichweiten über $300 \mathrm{~km}$

Jardin P, Esser A, Givone S, Eichenlaub T, Schleiffer J-E, Rinderknecht S (2019) the sensitivity in consumption of different vehicle drivetrain concepts under varying operating conditions: a simulative data driven approach. Vehicles 1(1):69-87. https://doi.org/10.3390/vehicles1010005

Meier T (2013) Multikriterielle Optimierung hybrider Antriebsstränge mittels statitistischer Versuchsplanung. Technische Universität Darmstadt, Institut für Mechatronische Systeme im Maschinenbau. Dissertation

Noreikat KE (2013) 10. Brennstoffzelle Einführung Und Grundlagen. MTZ Motortech Z 74(3):246-251. https://doi.org/10.1007/s35146-013-0057-y

Paganelli G, Delprat S, Guerra TM, Rimaux J, Santin JJ (2002) Equivalent consumption minimization strategy for parallel hybrid powertrains. In: IEEE 55th vehicular technology conference. Birmingham, AL, USA, 6-9 May 2002. Vehicular technology conference. IEEE, Piscataway, NJ, pp 2076-2081

Peters JF, Weil M (2018) Providing a common base for life cycle assessments of Li-ion batteries. J Clean Prod 171:704-713. https://doi.org/10.1016/j.jclepro.2017.10.016

Plötz G, Kühn W (2013) Markthochlaufszenarien für Elektrofahrzeuge. Edited by Fraunhofer ISI

Serrao L, Onori S, Rizzoni G (2009) ECMS as a realization of Pontryagin's minimum principle for HEV control. In: American control conference. 2009 American control conference. St. Louis, MO, USA, 6 Oct 2009-6 Dec 2009. American Automatic Control Council. IEEE, Piscataway, NJ, pp 3964-3969

statista (2019) Fahrleistung der Pkw in Deutschland im Jahr 2018 (in Kilometern). https://de.statista.com/ statistik/daten/studie/246069/umfrage/laufleistung-privater-pkw-in-deutschland/. Accessed on 25 Sept 2019

Thielmann A, Sauer A, Isenmann R, Wietschel M (2013) Technology roadmap energy storage for electric mobility 2030. Edited by Fraunhofer-Institut für System- und Innovationsforschung (ISI). Karlsruhe. https://www.isi.fraunhofer.de/content/dam/isi/dokumente/cct/lib/TRM-ESEM-2030_ en.pdf. Accessed on 19 Sept 2018

Wietschel M, Kühnbach M, Rüdiger D (2019) Die aktuelle Treibhausgas- emissionsbilanz von Elektrofahrzeugen in Deutschland. Working Paper Sustainability and Innovation No. S 02/2019. Edited by Fraunhofer ISI 
Publisher's Note Springer Nature remains neutral with regard to jurisdictional claims in published maps and institutional affiliations. 